\title{
АНАЛИЗ ОБОСНОВАННОСТИ ПЕНСИОННОЙ РЕФОРМЫ В РОССИИ
}

\author{
А. А. Викторова \\ Московский гуманитарный университет
}

Аннотация: В статье анализируются причины обоснованности российской пенсионной системы, направленной на осуществление коренных изменений в формировании пенсионного обеспечения и системы пенсионного страхования, на увеличение уровня и качества жизни граждан.

Ключевые слова: пенсионная реформа; пенсионный возраст; пенсионеры; продолжительность жизни; пенсия; возраст дожития

\section{ANALYSIS OF THE VALIDITY OF PENSION REFORM IN RUSSIA}

\author{
A. A. Viktorova \\ Moscow University for the Humanities
}

\begin{abstract}
The article analyses the reasons of the validity of the Russian pension reform aimed at the implementation of fundamental changes in the formation of pension provision and pension insurance system, at increasing the level and quality of life of citizens.
\end{abstract}

Keywords: pension reform; retirement age; pensioners; life expectancy; pen-sion; age of survival

Главной целью в системе пенсионного обеспечения в любой стране является гарантирование высокого уровня пенсии для граждан, которые имеют право на социально-пенсионный статус. Это обеспечивается накопленными активами за весь срок активной трудовой деятельности гражданина, а также мерами, направленными на дополнительную социальную поддержку пенсионеров (Ерлыков, 2016).

Сведения о количестве и структуре жителей считаются основной базой для определения численности получателей пенсий и плательщиков страховых взносов, двух составляющих элементов системы пенсионного страхования. Сведения о количестве жителей РФ за 2010-2018 гг. представлены в таблице 1 , подготовленной на основе данных Федеральной службы государственной статистики. 
Таблица 1. Численность населения РФ за 2010-2018 г2. по полу и возрастным группам

\begin{tabular}{|c|c|c|c|c|c|c|c|c|c|}
\hline \multirow{2}{*}{ Годы } & \multirow{2}{*}{\multicolumn{3}{|c|}{$\begin{array}{c}\text { Все население, } \\
\text { млн чел. }\end{array}$}} & \multicolumn{2}{|c|}{ 0-15 лет } & \multirow{4}{*}{$\begin{array}{c}\frac{16-60 \text { лет }}{\text { м }} \\
45,8\end{array}$} & \multirow{4}{*}{\begin{tabular}{|c|} 
16-55 лет \\
$\varkappa$ \\
48,8
\end{tabular}} & \multirow{4}{*}{$\begin{array}{c}\text { св. } 60 \text { лет } \\
\boldsymbol{M} \\
9,2\end{array}$} & \multirow{4}{*}{$\begin{array}{c}\text { св. } 55 \text { лет } \\
\text { ж } \\
17,4\end{array}$} \\
\hline & & & & $M$ & $\mathscr{C}$ & & & & \\
\hline \multirow{2}{*}{2010} & \multirow{2}{*}{142,9} & $\mathrm{M}$ & 66,1 & \multirow{2}{*}{11,1} & \multirow{2}{*}{10,6} & & & & \\
\hline & & ж & 76,8 & & & & & & \\
\hline \multirow{2}{*}{2011} & \multirow{2}{*}{142,9} & $\mathrm{M}$ & 66,1 & \multirow{2}{*}{11,3} & \multirow{2}{*}{10,7} & \multirow{2}{*}{45,7} & \multirow{2}{*}{48,7} & \multirow{2}{*}{9,1} & \multirow{2}{*}{17,4} \\
\hline & & ж & 76,8 & & & & & & \\
\hline \multirow{2}{*}{2012} & \multirow{2}{*}{143,0} & M & 66,1 & \multirow{2}{*}{11,4} & \multirow{2}{*}{10,8} & \multirow{2}{*}{45,6} & \multirow{2}{*}{48,6} & \multirow{2}{*}{9,2} & \multirow{2}{*}{17,5} \\
\hline & & ж & 76,9 & & & & & & \\
\hline \multirow{2}{*}{2013} & \multirow{2}{*}{143,3} & $\mathrm{M}$ & 66,3 & \multirow{2}{*}{11,7} & \multirow{2}{*}{11,1} & \multirow{2}{*}{45,2} & \multirow{2}{*}{48,1} & \multirow{2}{*}{9,8} & \\
\hline & & ж & 77,0 & & & & & & 19,1 \\
\hline & & M & 66,6 & & & & & & \\
\hline 2014 & 143,7 & ж & 77,1 & 12,0 & 11,4 & 44,9 & 47,6 & 10,1 & 19,6 \\
\hline 2015 & 1463 & M & 67,8 & 125 & 119 & 451 & 477 & 106 & 204 \\
\hline & 140,3 & ж & 78,5 & 12,5 & 11,9 & 45,1 & $4 /, 1$ & 10,0 & 20,4 \\
\hline & & M & 67,9 & & & & & & \\
\hline 2016 & 146,5 & ж & 78,6 & 12,8 & 12,2 & 44,6 & 47,2 & 10,9 & 20,9 \\
\hline 2017 & 1468 & M & 68,1 & 131 & 124 & $44 ?$ & 466 & 108 & 107 \\
\hline 2017 & 140,0 & ж & 78,7 & 15,1 & 12,4 & 44,2 & 40,0 & 10,0 & 19,1 \\
\hline & & $\mathrm{M}$ & 68,1 & & & & & & \\
\hline 2018 & 146,9 & ж & 78,8 & 13,2 & 12,6 & 43,8 & 46,1 & 11,1 & 20,1 \\
\hline
\end{tabular}

Численность населения РФ в 2010-2018 гг. увеличивалась. Наиболее значительным был рост в период 2012-2015 гг., когда численность населения увеличилась на 3,3 млн чел. В 2015-2018 гг. численность хотя и увеличивалась, но процент роста был не существенным - всего на 0,4\% или на 600 тыс. чел. В динамике отмечается сокращение мужчин и женщин в возрасте 16-60 лет. Однако, следует отметить, что численность мужчин и женщин в возрасте свыше 60 и 55 лет соответственно в динамике увеличивается.

Поступления средств в Пенсионный Фонд РФ на одного человека увеличились за 2010-2017 гг. в 2 раза, за последние два года увеличение составило 107,4\%. Это, конечно же, характеризуется очень положительно. Однако, в 2017 г. на одного пенсионера приходилось 103804,10 руб. в год или 8650,34 руб. в месяц, что является весьма небольшой суммой.

Несмотря на рост суммы пенсии (от 8272,7 руб. в 2012 г. до 13323,1 руб. в 2018 г., а в Московской области с 8848,5 тыс. руб. в 2012 г. до 14307,7 тыс. 
руб. в 2018 г.), пенсионное обеспечение в России показывает очевидное противоречие, состоящее, с одной стороны, в оптимизации расходов Пенсионного фонда РФ и внедрении трехуровневой системы пенсионного обеспечения, предусматривающей персонализацию пенсионных накоплений, а с другой стороны, в распространении социальных программ и увеличении социальных расходов государства, в т. ч. за счет институциональной инерции и увеличения нагрузки на работоспособных граждан. В связи с этим большую роль приобретает комплексная оценка принципов и механизмов совершенствования системы пенсионного обеспечения (Игнатов, 2017).

Трудности пенсионного обеспечения в Российской Федерации наиболее критически появятся к 2019 г., что связывается со старением население страны. На сегодняшний день в Российской Федерации живет 43177 тыс. пенсионеров при 72142,0 тыс. трудоспособного населения (в 2017 г.), т. е. $59,9 \%$. На сегодняшний день на одного пенсионера приходится 1,67 работника. При этом с 2014 г. совершается градационное снижение этого соответствия (рисунок 1).

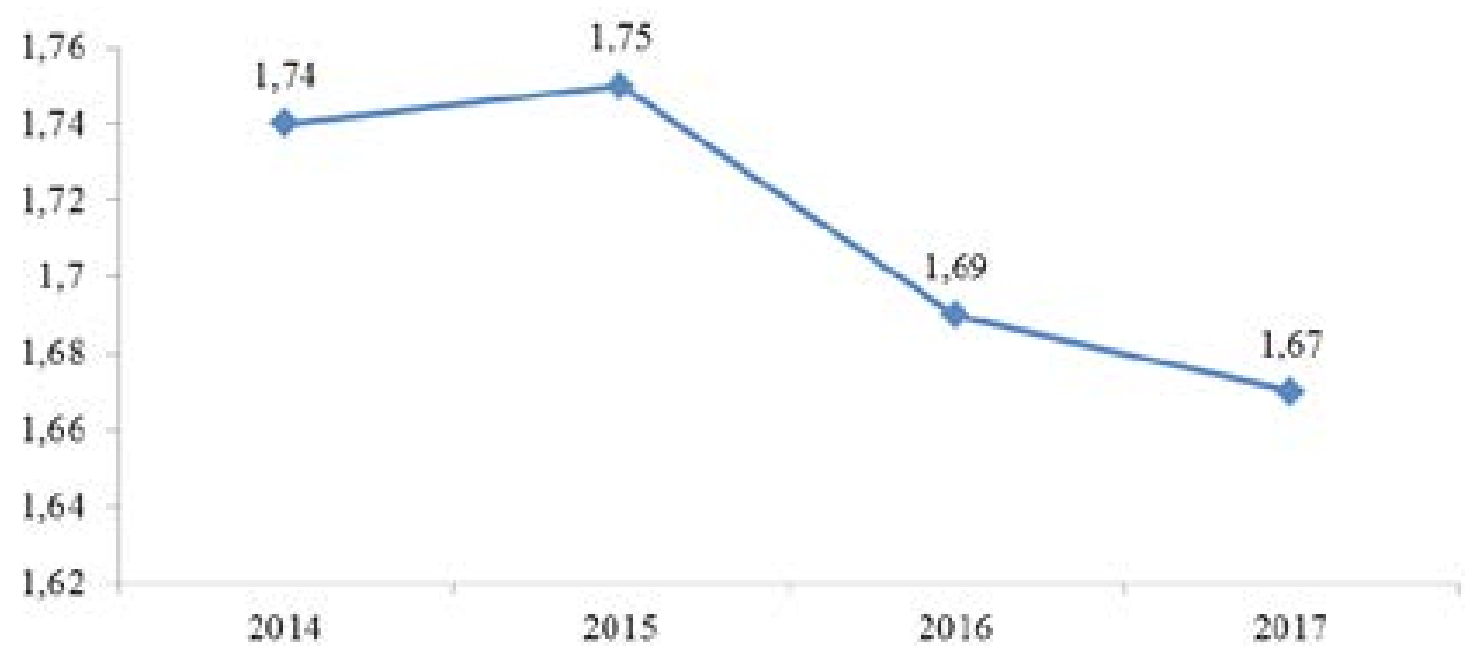

Рисунок 1. Динамика соотношения пенсионеров к рабочему населению (2014-2017 г2.)

В недалеком будущем число людей пенсионного возраста в сравнении с трудоспособным населением станет повышаться, и соотношение трудоспособных сотрудников и людей пенсионного возраста может составить к 2020 г. 1:1, т. е. одному трудоспособному рабочему придется гарантировать обеспечение одного пенсионера (Каспаров, 2018).

Большую трудность в пенсионном обеспечении играют граждане, родившиеся до 1967 г. и не вошедшие в новую пенсионную реформу, основанную на базовой, страховой и накопительной частей пенсий. Именно эти граждане (такая цепочка будет длиться вплотную до 2026 г., если на пен- 
сию уйдет последнее происхождение из представленной группы) будут получать «недостойную» величину пенсии. Также очень плачевными являются результаты инвестирования пенсионных накоплений (более 85\% людей 1967 г. рождения и моложе, имевшие право на накопительную часть пенсии) в последние несколько лет во Внешэкономбанк. Доходность вложения пенсионных накоплений за трехлетний период во Внешэкономбанк равнялась 8,01\% годовых, то есть инфляция «съела» значительные пенсионные накопления (Смугин, 2017).

Совместно с этим индивидуальные страховые компании в среднем принесли своим клиентам порядка 22\% (или 11\% с учетом инфляционной составляющей), а негосударственные пенсионные фонды - 16\% (7\% с учетом инфляционной составляющей). Специалисты советуют забирать заработанные финансы у государства и размещать их в частных фондах. Но более 85\% будущих пенсионеров хотят оставить заработанные финансы в управлении у государства, и насильственные инструменты никак не изменят данное положение (Михайлова, 2018).

В таблице 2, также на основе данных Росстата, указано количество работающих пенсионеров

Таблица 2. Количество работающих пенсионеров по видам пенсионного обеспечения и категориям пенсионеров, тыс. чел.

\begin{tabular}{|c|c|c|c|c|c|c|c|}
\hline \multirow[b]{2}{*}{ Показатель } & \multirow[b]{2}{*}{2013} & \multirow[b]{2}{*}{2014} & \multirow[b]{2}{*}{2015} & \multirow[b]{2}{*}{2016} & \multirow[b]{2}{*}{2017} & \multicolumn{2}{|c|}{ Темп роста, \% } \\
\hline & & & & & & $\begin{array}{c}2017 \kappa \\
2013\end{array}$ & $\begin{array}{c}2017 \kappa \\
2016\end{array}$ \\
\hline Работающие пенсионеры & 13669 & 14325 & 14917 & 15259 & 9883 & 72,3 & 64,8 \\
\hline $\begin{array}{l}\text { в \% к числу пенсионеров, которые } \\
\text { состоят в системе ПФР РФ }\end{array}$ & 33,7 & 34,9 & 36,0 & 35,7 & 22,9 & 68,0 & 64,1 \\
\hline \multicolumn{8}{|l|}{ из них получают пенсию: } \\
\hline$\square$ старость & 12626 & 13280 & 13872 & 14199 & 8791 & 69,6 & 61,9 \\
\hline и инвалидность & 806 & 795 & 773 & 759 & 679 & 84,2 & 89,5 \\
\hline $\begin{array}{l}\text { [ потеря кормильца (на каждого } \\
\text { нетрудоспособного члена семьи) }\end{array}$ & 11 & 10 & 17 & 23 & 46 & 418,2 & 200,0 \\
\hline 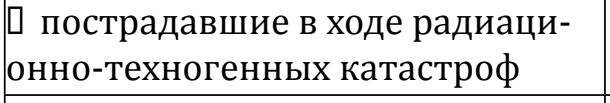 & 110 & 113 & 118 & 127 & 144 & 130,9 & 113,4 \\
\hline $\begin{array}{l}\text { (федеральные гос. гражданские } \\
\text { служащие }\end{array}$ & 18 & 20 & 20 & 22 & 12 & 66,7 & 54,5 \\
\hline $\begin{array}{l}\text { выслуга лет (пенсионеры-кос- } \\
\text { монавты) }\end{array}$ & 0,0 & 0,0 & 0,0 & 0,0 & 0,0 & - & - \\
\hline ( летчики-испытатели & 1 & 1 & 1 & 1 & 0,0 & - & - \\
\hline ( социальные & 97 & 106 & 116 & 128 & 211 & 217,5 & 164,8 \\
\hline
\end{tabular}


Численность работающих пенсионеров сократилась за 2013-2017 гг. на $27,7 \%$ и составила в 2017 г. 9883 тыс. чел., что составило $22,9 \%$ от общего числа пенсионеров. Из количества работающих пенсионеров значительное число пришлось на пенсионеров по старости - 89,0\%.

Средняя сумма назначенных пенсий по видам пенсионного обеспечения и категориям пенсионеров в РФ указана в таблице 3.

Большую пенсию получают за выслугу лет (пенсионеры-космонавты) - 451872,0 руб. в 2017 г. Потом идут летчики-испытатели, у которых пенсия составляет в 2017 г. 94308,4 руб. Федеральные госслужащие занимают третью позицию по сумме получаемой пенсии - 22500,8 руб. Пенсия по старости была равна 18172,5 руб. Наименьшая пенсия приходилась по потере кормильца - всего 13175,7 руб.

Таблица 3. Средняя сумма пенсии по видам пенсионного обеспечения и категориям пенсионеров в РФ, руб.

\begin{tabular}{|c|c|c|c|c|c|c|c|}
\hline \multirow[b]{2}{*}{ Показатель } & \multirow[b]{2}{*}{2013} & \multirow[b]{2}{*}{2014} & \multirow[b]{2}{*}{2015} & \multirow[b]{2}{*}{2016} & \multirow[b]{2}{*}{2017} & \multicolumn{2}{|c|}{ Темп роста, \% } \\
\hline & & & & & & $\begin{array}{c}2017 \kappa \\
2013\end{array}$ & $2017 \kappa$ \\
\hline Все пенсионеры, в т. ч.: & 9153,6 & 10029,7 & 10888,7 & 12080,9 & 17425,6 & 190,4 & 144,2 \\
\hline प старость & 9790,1 & 10716,4 & 11569,1 & 12830,4 & 18172,5 & 185,6 & 141,6 \\
\hline [ инвалидность & 6106,3 & 6669,2 & 7209,9 & 8040,1 & 13253,7 & 217,0 & 164,8 \\
\hline $\begin{array}{l}\text { (потеря кормильца (на } \\
\text { каждого нетрудоспособно- } \\
\text { го члена семьи) }\end{array}$ & 5959,0 & 6598,6 & 7185,1 & 7924,9 & 13175,7 & 221,1 & 166,3 \\
\hline $\begin{array}{l}\text { प пострадавшие в ходе ра- } \\
\text { диационно-техногенных } \\
\text { катастроф }\end{array}$ & 8402,6 & 8639,2 & 9779,2 & 10766,7 & 16261,1 & 193,5 & 151,0 \\
\hline $\begin{array}{l}\text { प федеральные гос. граж- } \\
\text { данские служащие }\end{array}$ & 12422,9 & 14020,1 & 15550,0 & 17186,4 & 22500,8 & 181,1 & 130,9 \\
\hline $\begin{array}{l}\text { ( выслуга лет (пенсионе- } \\
\text { ры-космонавты) }\end{array}$ & 64057,4 & 364283,5 & 361989,6 & 446260,3 & 451872,0 & 705,4 & 101,3 \\
\hline 口 летчики-испытатели & 64321,4 & 67704,0 & 76855,4 & 85736,2 & 94308,4 & 146,6 & 110,0 \\
\hline — социальные & 5919,0 & 6446,4 & 7548,3 & 8302,4 & 13644,4 & 230,5 & 164,3 \\
\hline
\end{tabular}


Средняя величина пенсии составляла 17425,6 руб. в 2017 г. (таблица 4). Таблица 4. Средний размер пенсии в зависимости от пола и места проживания пенсионера в РФ, руб.

\begin{tabular}{|c|c|c|c|c|c|c|c|}
\hline \multirow[b]{2}{*}{ Показатель } & \multirow[b]{2}{*}{2013} & \multirow[b]{2}{*}{2014} & \multirow[b]{2}{*}{2015} & \multirow[b]{2}{*}{2016} & \multirow[b]{2}{*}{2017} & \multicolumn{2}{|c|}{ Темп роста, \% } \\
\hline & & & & & & $\begin{array}{c}2017 \kappa \\
2013\end{array}$ & $\begin{array}{c}2017 \kappa \\
2016\end{array}$ \\
\hline Пенсионеры, из них: & 9153,6 & 10029,7 & 10888,7 & 12080,9 & 17425,6 & 190,4 & 144,2 \\
\hline ( женщины & 8967,2 & 9846,6 & 10663,7 & 11852,6 & 17200,1 & 191,8 & 145,1 \\
\hline ( мужчины & 9534,4 & 10404,1 & 11346,5 & 12543,2 & 17882,6 & 187,6 & 142,6 \\
\hline \multicolumn{8}{|l|}{ Пенсионеры, проживающие: } \\
\hline [ в сельской местности & 8243,4 & 9008,1 & 9801,8 & 10736,9 & 16045,8 & 194,7 & 149,4 \\
\hline $\begin{array}{l}\text { в городской местно- } \\
\text { сти }\end{array}$ & 9527,3 & 10445,5 & 11305,2 & 12595,2 & 17945,4 & 188,4 & 142,5 \\
\hline
\end{tabular}

Сопоставление суммы пенсии по полу показывает, что у мужчин пенсия несколько больше, нежели у женщин (в 2017 г. 17882,6 руб. против 17200,1 руб.). Пенсионеры, которые живут в городской местности, имеют более высокую пенсию, чем сельские пенсионеры (в 2017 г. 17945,4 руб. против 16045,8 руб.).

Ухудшение пенсионного обеспечения в России стало очевидным за последнее время, что связывается с финансово-экономической ситуацией в стране. Сложившаяся в России современная система пенсионного обеспечения характеризуется целым перечнем существенных недостатков и, главное, не может обеспечить стабильное исполнение обязательств государства перед пенсионерами в ближайшем будущем. Трудность с задержками выплаты государственных пенсий в некоторой мере была решена, а вот проблема сопоставления размера пенсии социальным нуждам людей до сих пор остается актуальной (Башева, 2017).

Также следует отметить, что вероятность дожития до пенсии россиян будет постепенно сокращаться, что указано в таблице 5.

Таблица 5. Вероятность дожития до пенсии россиян

\begin{tabular}{|c|c|c|c|}
\hline Год рождения & $\begin{array}{c}\text { До 55 лет, в } \\
\%\end{array}$ & До пенсионного возраста, в \% & Выходна пенсию, лет \\
\hline \multicolumn{3}{|c|}{} \\
\hline \multicolumn{4}{|c|}{ Женщины } \\
\hline 1964 & 99,4 & 98,9 & 56 \\
\hline 1965 & 99,0 & 97,8 & 57 \\
\hline 1966 & 98,6 & 97,0 & 58 \\
\hline
\end{tabular}


Научные труды Московского гуманитарного университета 2019 № 2

\begin{tabular}{|l|l|l|l|}
\hline \multicolumn{1}{|c|}{90,2} & 96,2 & 59 \\
\hline 1967 & 97,9 & 95,5 & 60 \\
\hline 1969 & 97,7 & 94,9 & 61 \\
\hline 1970 & 97,5 & 94,3 & 62 \\
\hline 1971 & 97,4 & 93,5 & 63 \\
\hline \multicolumn{5}{|c|}{} & Мужчины & \\
\hline 1959 & 97,9 & 95,8 & 61 \\
\hline 1960 & 95,9 & 91,7 & 62 \\
\hline 1961 & 94,6 & 88,9 & 63 \\
\hline 1962 & 93,1 & 85,6 & 64 \\
\hline 1963 & 91,8 & 82,6 & 65 \\
\hline
\end{tabular}

У сегодняшних пенсионеров-мужчин шансы дожить до пенсии будут сокращаться из года в год. Так, среди мужчин 1959 г. р. вероятность дожить до нового пенсионного возраста составит 95,8\% (61 г.), среди родившихся в 1960 г. - уже 91,7\% (62 г.), в 1961 г. - 88,9\% (63 г) и т. д. Данные расчеты затрагивают мужчин, доживших до 2018 г., и не учитывают тех, кто, родившись в период с 1959 по 1962 год, скончался раньше. Вероятность дожития женщин до новых пенсионных возрастов выше, чем у мужчин. Для 1964 г. она составляет 98,9\%, для 1965 г. - 97,8\%, для 1966 г. - 97\%.

Таким образом, для того, чтобы в престарелом возрасте у людей никак не возникало чувство незащищенности и была возможность вести полноценный образ жизни, существуют государственные пенсии. Однако, как показывает практика, современная система пенсионного обеспечения далеко не идеальна, а получаемые пожилыми людьми пенсии не позволяют им быть в полной мере удовлетворенными своим социально-экономическим положением. Именно поэтому, как подчеркивают исследователи:

1. Правительству следует четко устанавливать размер гарантий и ответственность, которую сможет взять на себя в процессе пенсионного обеспечения россиян, сформировав им условия для формирования их пенсионных накоплений (Туманьянц, 2018);

2. Основополагающим средством в разрешении пенсионных трудностей является система формирования и становления региональных накопительных пенсионных фондов, которые с учетом региональной специфики, могут улучшить качество жизни пенсионеров в перспективе, а с другой стороны, приведет к социально-экономическому формированию регионов 
путем перечисления на такие цели образованные в них ресурсы (Сидоров, 2017);

3. Государству необходимо мотивировать работодателей на участие в пенсионном обеспечении своих работников. Для этого следует сформировать систему налоговых льгот и прочих форм стимулирования для добровольных корпоративных пенсионных программ, а также упорядочить их законодательное регламентирование (Ермеева, 2016).

Также, следует объяснять гражданам значимость и целесообразность создания накопительной части пенсии.

\section{СПИСОК ЛИТЕРАТУРЫ}

Башева, И. В. (2017) Трудности пенсионной реформы в России // Сервис в России и за рубежом. № 1. С. 273-282.

Ерлыков, Д. Н. (2016) Пенсионное обеспечение граждан: проблемы и решения // Юридический журнал. № 3. С. 273-279.

Ермеева, С. С. (2016) Трудности в реформировании пенсионного обеспечения в РФ // Известия РГПУ им. А. И. Герцена. № 120. С. 290-295.

Игнатов, И. В. (2017) Тенденции развития системы пенсионного обеспечения в России // Известия РГПУ им. А. И. Герцена. № 73. С. 45-49.

Каспаров, Н. М. (2018) Система пенсионного обеспечения в РФ // Концептуальные основы. № 5. С. 65-70.

Михайлова, Е. В. (2018) Инструменты современной системы пенсионного обеспечения в России // TerraEco. № 3. С. 54-63.

Сидоров, А. Н. (2017) Проблемы пенсионной реформы в современной России // Вестник ВГУ. № 1. С. 100-102.

Смугин, Н. П. (2017) Система пенсионного обеспечения // Вестник ВУ им. В. Н. Татищева. № 2. С. 1-7.

Туманьянц, К. А. (2018) Проблемы пенсионной реформы в РФ и инструменты их решения // Вестник ВГУ. № 2. С. 140-147.

Дата поступления: 15.03.3019 2.

Викторова Анастасия Алексеевна - студент магистратуры направления «Государственное и муниципальное управление» Московского гуманитарного университета. Адрес: 111395, Россия, г. Москва, ул. Юности, д. 5. Тел.: +7(910) 483-78-90. Эл. адрес: 1vian1996@mail.ru

Viktorova Anastasiya Alekseyevna, Graduate Student, programme of study "State and Municipal Administration", Moscow University for the Humanities. Postal address: 5, Yunosti St., Moscow, Russian Federation, 111395. Tel.: +7 (910) 483-78-90. E-mail: 1vian1996@mail.ru 


\section{Для цитирования:}

Викторова А. А. Анализ обоснованности пенсионной реформы в России [Электронный ресурс] // Научные труды Московского гуманитарного университета. 2019. № 2. URL: http://journals.mosgu.ru/trudy/article/view/961 (дата обращения: дд.мм.гг.). DOI: 10.17805/trudy.2019.2.4 